\title{
Mycobacterium tuberculosis P-Type ATPases: Possible Targets for Drug or Vaccine Development
}

\author{
Lorena Novoa-Aponte and Carlos Yesid Soto Ospina \\ Chemistry Department, Faculty of Sciences, Universidad Nacional de Colombia, Carrera 30 No. 45-03, Bogotá, Cundinamarca 111321, \\ Colombia \\ Correspondence should be addressed to Carlos Yesid Soto Ospina; cysotoo@unal.edu.co
}

Received 7 February 2014; Accepted 23 June 2014; Published 10 July 2014

Academic Editor: Armando Acosta

Copyright (C) 2014 L. Novoa-Aponte and C. Y. Soto Ospina. This is an open access article distributed under the Creative Commons Attribution License, which permits unrestricted use, distribution, and reproduction in any medium, provided the original work is properly cited.

\begin{abstract}
Tuberculosis (TB) has been the biggest killer in the human history; currently, Mycobacterium tuberculosis (Mtb) kills nearly 2 million people each year worldwide. The high prevalence of TB obligates the identification of new therapeutic targets and the development of anti-TB vaccines that can control multidrug resistance and latent TB infections. Membrane proteins have recently been suggested as key targets for bacterial viability. Current studies have shown that mycobacteria P-type ATPases may play critical roles in ion homeostasis and in the response of mycobacteria to toxic substances in the intraphagosomal environment. In this review, we bring together the genomic, transcriptomic, and structural aspects of the P-type ATPases that are relevant during active and latent $M t b$ infections, which can be useful in determining the potential of these ATPases as drug targets and in uncovering their possible roles in the development of new anti-TB attenuated vaccines.
\end{abstract}

\section{Introduction}

Mycobacterium tuberculosis $(M t b)$, the causative agent of tuberculosis (TB), kills approximately one person every 25 seconds which means that 2 million people worldwide die of TB every year [1]. The current high TB prevalence is mainly due to pervasive poverty, coinfection with human immunodeficiency virus (HIV), and the emergence of $M t b$ strains that are resistant to the common drugs used to treat TB (MDR and XDR strains). Each of these factors has positioned this infectious disease as a major public health problem [2]. Controlling TB is complicated due to several factors, of which the most important is the capacity of $M t b$ to persist for long periods of time in adverse conditions into macrophages $[3,4]$. In the intraphagosomal environment, mycobacteria face ion and nutrient deficiencies, as well as an arsenal of toxic substances, such as acid hydrolases, antimicrobial peptides, reactive oxygen and nitrogen species, and high concentrations of heavy metal cations, among others [5-11]. The outcome of $M t b$ infection would be represented as a distribution between active TB and latent TB on the basis of the presence or absence of clinical symptoms, respectively, making TB difficult to control and diagnose [12]. Thus, it is essential to identify specific therapeutic targets that can be used to control latent and active TB infections. In this regard, a new anti-TB drug should achieve the following: (i) shorten the duration and dose of treatment; (ii) be active against both MDR and XDR Mtb strains; (iii) be able to eradicate latent TB; and (iv) be capable of being coadministered with drugs to treat HIV $[13,14]$.

The identification of new therapeutic targets in mycobacteria takes into account aspects that allow mycobacteria to adapt and succeed during the infectious process. Based on the current knowledge, P-type ATPases might be important as they transport metal cations across the plasma membranes of both the host and pathogen and generate electrochemical gradients necessary for the transport of other solutes and for the protection of the cell against the toxic substances in the phagosomes $[15,16]$. For example, the deletion of the $M t b$ CtpV P-type ATPase reduces the resistance of the tubercle 
bacilli to the toxic levels of copper ions in its surroundings. This deletion also diminishes the bacteria's ability to grow inside the lungs in murine infection models, suggesting that this pump is required to maintain the virulence of the tubercle bacilli [17].

The aim of this review is to present the potential of $M t b$ P-type ATPases as possible therapeutic targets and to assess their usefulness in the development of vaccines for TB control. This potential will be evaluated based on three different aspects: (i) experimental evidence for differential gene expression patterns of these ion transporters during critical mycobacterial infection processes and treatment with toxic substances; (ii) the existence of close homologs of the $M t b$ P-type ATPases in other pathogens and their considerable divergence with the human P-type transporters; and (iii) the apparent impairment of $M t b$ virulence after deleting the aforementioned ion pumps.

\section{P-Type ATPases}

In general, the ATPase enzymes are membrane proteins that perform energetically unfavorable processes, such as folding and degrading proteins, the initiation of replication, DNA repair, and the transport of substances [18], using the energy released during ATP hydrolysis. Specifically, Ptype ATPases are active transporters of metal cations that are autophosphorylated on a conserved aspartate residue during each catalytic cycle, and these enzymes can be inhibited by orthovanadate [19]. All P-type ATPases have multiple domains (Figure 1): three cytoplasmic domains (A, actuator; $\mathrm{N}$, nucleotide binding; $\mathrm{P}$, phosphorylation) and two domains embedded in the membrane ( $\mathrm{T}$, transport; S, class specific support) $[15,19-21]$. During the catalytic cycle, the phosphorylation process is catalyzed by the $\mathrm{N}$ domain (protein kinase activity), while dephosphorylation is catalyzed by the A domain (phosphatase activity). The phosphorylation/dephosphorylation cycle is accompanied by conformational changes in the enzyme that allow cation transport, which is mediated by the $\mathrm{T}$ domain, which also exhibits amino acid determinants that define the ion specificity of each type of pump $[15,19]$.

2.1. The Tubercle Bacillus Has a Large and Unusual Number of P-Type ATPases. Mtb has 11 P-type ATPases (CtpA, CtpB, CtpC, CtpD, CtpE, CtpF, CtpG, CtpH, CtpI, CtpJ, and $\mathrm{CtpV}$ ), as shown in Table 1. Seven of these enzymes have been identified as possible carriers of heavy metal cations, suggesting their possible role in the intraphagosomal survival of $M t b$ [22]. Metals, such as iron, magnesium, cobalt, copper, manganese, and zinc, are essential for all forms of life, as they act as members of prosthetic groups or as cofactors of many enzymes. In general, microorganisms only need traces of these micronutrients for proper cell function; indeed, excessive accumulation is toxic [23]. An overabundance of metals can block enzymatic functional groups, displace essential metal ions, and modify the active conformations of biomolecules [24]. In response, cells have developed strategies to maintain a balance between the entrance and

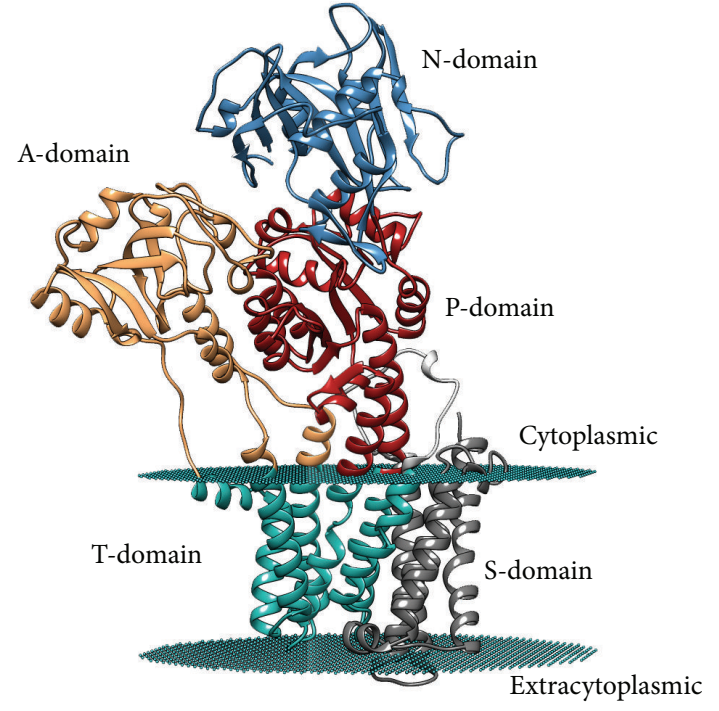

FIGURE 1: Structural organization of the five P-type ATPase domains. M. tuberculosis CtpF tertiary structure model, generated using the SWISS-MODEL server (http://swissmodel.expasy.org/) in automated mode and the structure of the Sarco(endo)plasmic reticulum calcium ATPase 1 from Oryctolagus cuniculus (PDB accession number 3AR4) as template. The model was modified using the PPM server to include the possible location of the lipid bilayer, which is displayed in cyan dummies that correspond to the location of the carbonyl groups in the bilayer.

the exit of cations to preserve their concentrations at nutrient levels. Transport systems involved in cell homeostasis must be pivotal for the virulence of intracellular pathogens, such as $M t b$ [17]. The large number of P-type ATPases encoded in the genome of $M t b$ is twice the size of those encoded in the genomes of saprophyte mycobacteria, such as M. smegmatis [25]; this may strongly suggest the importance of this type of metal cation transporters to the virulence of the tubercle bacillus [26, 27].

2.2. P-Type ATPases Have Been Associated with the Intracellular Survival of Mycobacteria. Recently, it has been established that the heavy metal P-type ATPases CtpC and CtpD are necessary for murine infection with $M t b$ [28]. In line with this discovery, it has been proposed that the heavy metal pumps CtpC, CtpV, and CtpG are part of a defense mechanism used by mycobacteria to survive for long periods of time within human phagocytic cells $[11,17]$. For example, deletion of CtpC, a $\mathrm{Zn}^{2+}$ efflux system, in $M t b$ cells causes the tubercle bacilli to be hypersensitive to physiologic $\mathrm{Zn}^{2+}$ concentrations, thereby affecting their capacity to grow inside macrophages [11]. In general, it could be suggested that deletion of nutrient uptake systems significantly attenuates the growth of $M t b$ strains [28].

\subsection{Mycobacterium tuberculosis P-Type ATPases Are Located} in the Plasma Membrane. In general, membrane proteins are considered key therapeutic targets due to their roles as substance carriers and mediators in the interactions between 
TABLE 1: Mtb P-type ATPases and related human counterparts. The search for homologous ATPases was performed using the Blastp tool (http://blast.ncbi.nlm.nih.gov/). The table is organized according to the levels of similarity based on the "scores" from the pairwise alignment obtained using MATCHER (http://mobyle.pasteur.fr).

\begin{tabular}{lccc}
\hline Mtb P-type ATPase & & Closet human homologs \\
Identifier* & Human P-type ATPase \\
\hline CtpF (Rv1997) & Pairwise alignment score & P98194 & Ca-transporting ATPase \\
CtpV (Rv0969) & 1272 & Q04656 & Cu-transporting ATPase 1 \\
CtpA (Rv0092) & 886 & P35670 & Cu-transporting ATPase 2 \\
CtpB (Rv0103c) & 727 & P35670 & Cu-transporting ATPase 2 \\
CtpC (Rv3270) & 722 & P35670 & Cu-transporting ATPase 2 \\
CtpI (Rv0107c) & 539 & Q13733 & Na/K-transporting ATPase $\alpha$ 4 \\
CtpG (Rv1992c) & 450 & P35670 & Cu-transporting ATPase 2 \\
CtpD (Rv1469) & 441 & P35670 & Cu-transporting ATPase 2 \\
CtpJ (Rv3743c) & 392 & Q04656 & Cu-transporting ATPase 1 \\
CtpH (Rv0425c) & 377 & Q93084 & SERCA Ca ATPase \\
CtpE (Rv0908) & 334 & P98194 & Ca-transporting ATPase \\
\hline
\end{tabular}

* UniProt identifiers (http://www.uniprot.org/).

pathogens and the surrounding environment. Additionally, the P-type ATPases are located in the plasma membrane, which makes them highly accessible [29] to antimicrobial compounds. These properties are advantageous for the development of new drugs because the permeability of this biological barrier does not have to be resolved [14]. Consistent with this assertion, certain anti-TB drugs, such as diarylquinolines (TMC207) and benzothiazines (BTZ043), have been recently developed to target molecules located in the mycobacterial plasma membrane [14]. Therefore, $M t b$ P-type ATPases could be possible targets for the design of inhibitors that are capable of acting on their targets without being internalized by the mycobacterial cell.

While the location of P-type ATPases on the plasma membrane may be advantageous for their accessibility, this location also could be problematic, as it can be difficult to determine the tertiary structure of this kind of proteins which is useful for molecular docking experiments. The appropriate tertiary structure of target proteins is crucial for a rational drug design. An optional strategy may involve the use of the crystal structures of close homologues that share at least $70 \%$ identity [30]. Certainly, the constant development of crystallization methods for membrane proteins will make this strategy more feasible in the near future.

\section{P-Type ATPases Are Useful Drug Targets}

For the development of rational drugs against specific cellular targets, information about the chemical structure of similar inhibitors is pivotal for the design of new molecules with improved affinities and diminished minimal inhibitory concentrations. For example, the anti-TB drug rifabutin is a rifamycin derivative that was developed to replace rifampicin in the treatment of HIV-TB coinfections [14]. On the other hand, P-type ATPases are the general targets of many drugs $[18,29]$. For example, omeprazole, which is used to treat gastric ulcers, acts as an inhibitor of an $\mathrm{H}^{+} / \mathrm{K}^{+}$ATPase, and thapsigargin, a $\mathrm{Ca}^{2+}$ SERCA ATPase inhibitor, is used as a prodrug for prostate cancer treatment [29]. Interestingly, inhibitors of P-type ATPases have also been developed as antibiotics; for example, clotrimazole, an antifungal that blocks certain $\mathrm{Ca}^{2+}$ ATPase, and chloroquine/artemisinin, which inhibit Plasmodium falciparum P-type ATPases, have been used as antimalarial drugs [29].

\section{Potential of P-Type ATPases as Targets for the Development of Novel Antituberculous Drugs}

Currently, the exploration for new anti-TB drugs is based, in part, on $M t b$ gene expression profile data from different stress conditions $[4,30]$. In this review, the potential of $M t b \mathrm{P}-$ type ATPases as therapeutic targets is specifically considered according to the following: (i) the gene expression profiles of the P-type ATPases in $M t b$ facing toxic substances and under both latent infection and active disease; (ii) their roles in virulence; and (iii) their structural divergences from human P-type ATPases.

\section{Transcriptional Behavior of Mycobacterium tuberculosis P-Type ATPases under Stress Conditions}

The transcriptional behavior of P-type ATPases in the presence of toxic substances and in models of latent infection and active disease could suggest strategies used by $M t b$ to colonize, interact with, and/or alter the functions of the host cells [31]. A detailed review of the published $M t b$ gene expression profiles (Table 2) shows the activation or repression of most of the $M t b$ P-type ATPases under stress conditions.

5.1. The ctpF, ctpG, and ctpC Genes Are Preferentially Activated in the Presence of Toxic Substances. In addition to punctual mutations in drug targets, $M t b$ possesses alternative antibiotic 
TABLE 2: Studies investigating M. tuberculosis gene expression profiles under stress conditions.

\begin{tabular}{|c|c|c|c|c|}
\hline Model & & Experimental conditions & Methodology** & References \\
\hline MDR strains & 1 & $\begin{array}{l}\text { Comparison between MDR and } \\
\text { H37Rv strains }\end{array}$ & MA & $\begin{array}{l}\text { Chatterjee et al. } \\
\text { (2013) [32] }\end{array}$ \\
\hline \multirow{4}{*}{$\begin{array}{l}\text { Toxic } \\
\text { substances } \\
\text { (in vitro) }\end{array}$} & 2 & SDS & $\begin{array}{l}\text { RT-qPCR and } \\
\text { MA }\end{array}$ & $\begin{array}{l}\text { Manganelli et al. } \\
\quad \text { (2001) [33] }\end{array}$ \\
\hline & 3 & $\begin{array}{l}\text { Isoniazid, isoxyl, tetrahydrolipstatin, } \\
\text { SRI \#221, SRI \#967, and SRI \#9190 }\end{array}$ & MA & $\begin{array}{l}\text { Waddell et al. } \\
\text { (2004) [34] }\end{array}$ \\
\hline & 4 & Sodium hypochlorite & MA & $\begin{array}{l}\text { Jang et al. } \\
(2009) \text { [35] }\end{array}$ \\
\hline & 5 & Peracetic acid & MA & $\begin{array}{l}\text { Nde et al., } \\
(2011)[36]\end{array}$ \\
\hline \multirow{4}{*}{$\begin{array}{l}\text { Toxic substances } \\
\text { related to } \\
\text { infection } \\
\text { (in vitro) }\end{array}$} & 6 & Oxidative stress & MA & $\begin{array}{l}\text { Manganelli et al. } \\
\text { (2002) [37] }\end{array}$ \\
\hline & 7 & Nitrogen reactive substances & $\begin{array}{l}\text { RT-qPCR and } \\
\text { MA }\end{array}$ & $\begin{array}{l}\text { Ohno et al. } \\
\text { (2003) [38] }\end{array}$ \\
\hline & 8 & Physiological levels of copper & RT-qPCR & $\begin{array}{l}\text { Ward et al. } \\
(2008)[39]\end{array}$ \\
\hline & 9 & Physiological levels of zinc & $\begin{array}{l}\text { RT-qPCR and } \\
\text { MA }\end{array}$ & $\begin{array}{l}\text { Botella et al. } \\
\text { (2011) [11] }\end{array}$ \\
\hline \multirow{8}{*}{$\begin{array}{l}\text { Latency } \\
\text { (in vitro) }\end{array}$} & 10 & Hypoxia & MA & $\begin{array}{l}\text { Sherman et al. } \\
\text { (2001) [40] }\end{array}$ \\
\hline & 11 & Hypoxia & MA & $\begin{array}{l}\text { Bacon et al. } \\
(2004)[41]\end{array}$ \\
\hline & 12 & Hypoxia and nitric oxide & MA & $\begin{array}{l}\text { Voskuil et al. } \\
\text { (2003) [42] }\end{array}$ \\
\hline & 13 & Steady culture & $\begin{array}{l}\text { RT-qPCR and } \\
\text { MA }\end{array}$ & $\begin{array}{l}\text { Kendall et al. } \\
\text { (2004) [43] }\end{array}$ \\
\hline & 14 & Nonreplicating persistence (NRP) & MA & $\begin{array}{l}\text { Muttucumaru et al } \\
\text { (2004) [44] }\end{array}$ \\
\hline & 15 & Nonreplicating persistence (NRP) & Proteomic & $\begin{array}{l}\text { Cho et al. } \\
(2006)[13]\end{array}$ \\
\hline & 16 & Starvation & MA & $\begin{array}{l}\text { Hampshire et al. } \\
\text { (2004) [45] }\end{array}$ \\
\hline & 17 & Starvation & MA & $\begin{array}{l}\text { Betts et al. } \\
(2002)[46]\end{array}$ \\
\hline \multirow{5}{*}{$\begin{array}{l}\text { Infection } \\
\text { (in vivo) }\end{array}$} & 18 & Mouse macrophage infection & MA & $\begin{array}{l}\text { Schnappinger et al. } \\
\text { (2003) [47] }\end{array}$ \\
\hline & 19 & Mouse lung infection & MA & $\begin{array}{l}\text { Talaat et al. } \\
(2004)[31]\end{array}$ \\
\hline & 20 & Artificial granulomas in mice & MA & $\begin{array}{l}\text { Karakousis et al. } \\
\quad(2004)[48]\end{array}$ \\
\hline & 21 & $\begin{array}{l}\text { Human dendritic cells and } \\
\text { macrophage infection }\end{array}$ & MA & $\begin{array}{l}\text { Tailleux et al. } \\
\text { (2008) [49] }\end{array}$ \\
\hline & 22 & Human lung infection & RT-qPCR & $\begin{array}{l}\text { Kumar et al. } \\
\text { (2011) [50] }\end{array}$ \\
\hline
\end{tabular}

** MA, microarrays.

resistance mechanisms, such as efflux pumps, DNA repair proteins, and membrane transporters [32]. Therefore, it is of interest to know which transporters are overexpressed during the exposure of $M t b$ to toxic substances.

The CtpF and CtpC P-type ATPases are the most overexpressed transporters when $M t b$ is treated with toxic substances, including isoniazid, tetrahydrolipstatin, isoxyl, SRI
\#221, SRI \#967, SRI \#9190 [34], SDS [33], sodium hypochlorite [35], and peracetic acid [36] (Figure 2), which suggests that these transporters could contribute to the intrinsic resistance of $M t b$ to those compounds. Furthermore, CtpF, which is a possible alkali/alkaline earth metal cation transporter, is almost 60 -fold overexpressed when mycobacteria face nitrogen reactive substances [38], while CtpG, a possible $\mathrm{Zn}^{2+}$ 


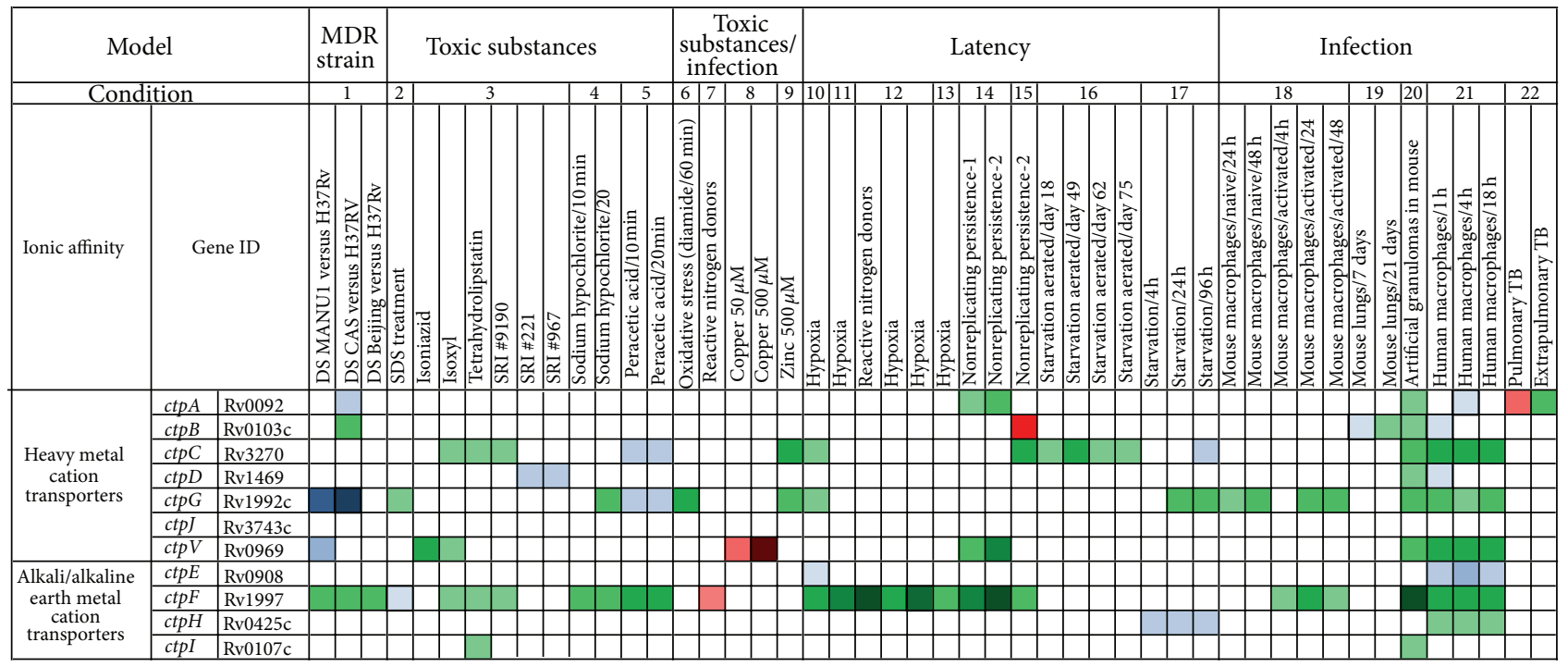

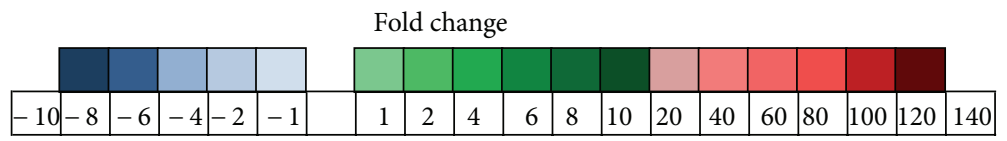

Figure 2: General scheme of the transcriptional behaviors of the Mtb P-type ATPases under stress conditions, such as toxic substances, latency, and infection. This figure was generated from the information reported in the references of Table 2 and is organized depending on the experimental conditions, which were numbered in the same table.

ATPase, is activated in response to the oxidant agent diamide [37]. As expected, the genes that respond to heavy metal poisoning $\left(\mathrm{Cu}^{2+}\right.$ and $\left.\mathrm{Zn}^{2+}\right)$ are the genes predicted to encode heavy metal cation P-type ATPases (ctpG, ctpC, and $c t p V)$ $[11,39]$.

\subsection{CtpF and CtpC Are Activated under In Vitro Models} of Hypoxia and Starvation. Nearly 95\% of Mtb lung infections are acquired via aerosol progress to latent TB [14]. Therefore, many models of hypoxia, starvation, and murine infection have been developed to simulate the dormant state of mycobacterial latent infection, in an attempt to understand the mechanisms of $M t b$ persistence. However, these models cannot entirely represent the complexity of the granuloma $[4,48]$. In the in vitro models of hypoxia, it has been observed that the $c t p F$ gene is highly overexpressed (15 times) during low oxygen tension under microaerophilic and anaerobic conditions, suggesting a key role of the CtpF transporter in hypoxia $[43,51]$. Certain heavy metal cation Ptype ATPase genes, including $c t p C, \operatorname{ctp} A, \operatorname{ctp} V$, and $c t p B$, are also activated under hypoxic conditions, but at a lower level $[13,40,44]$ (Figure 2). However, $c t p F$ is the only $M t b$ P-type ATPase gene that is regulated by the global latency regulator $\operatorname{dos} R[43,51]$. Additionally, models that simulate nutrient starvation, a characteristic of the caseous compartments in which the tubercle bacilli reside during the latent infection (granuloma), show that the genes that code for the heavy metal pumps CtpC and CtpG are overexpressed, while CtpH is suppressed under these stress conditions $[45,46]$.
Alternatively, gene regulation data also show that, during the dormant phase, there is a large attenuation of the $M t b \mathrm{~F}_{0^{-}}$ $\mathrm{F}_{1}$-ATP synthase pump, indicating impaired ATP production during the nonreplicative state of mycobacteria [4]. A diminished ATP level would limit the overall activity of the ATPase enzymes due to the scarcity of energy sources; conversely, under this particular stress condition, P-type ATPases have been shown to be overexpressed, a biological phenomenon that highlights the importance of this type of transporters in the tubercle bacilli persistence during the latent infection. The above observations lead us to postulate that P-type ATPases could be exploited as therapeutic targets if their roles in persistence were interpreted in the opposite direction. For example, it would be possible that the activation of $\mathrm{Mtb} \mathrm{P}-$ type ATPases during the dormant phase (using a stimulating compound) could cause a leak in the mycobacterial ATP stores, resulting in the physiological instability or death of the tubercle bacilli or forcing the bacilli to return to an active state, in which the bacteria are susceptible to common anti-TB drugs [4]. In this regard, a mycobacterial $\mathrm{F}_{1}-\mathrm{F}_{0}$ ATP synthase inhibitor, such as TMC207 [52], could be used in combination with compounds that mediate $M t b$ P-type ATPase activation, thus promoting ATP consumption and avoiding ATP synthesis in the pathogen.

5.3. The Majority of Mycobacterium tuberculosis P-Type ATPases Are Activated In Vivo. When designing new anti-TB drugs, it is important that the selected therapeutic targets play 
an essential role in both active disease and latent $M t b$ infections $[14,30]$. Therefore, it is necessary to identify gene products that are pivotal for the persistence of $M t b$ within phagocytic cells [53]. Thus, it has been shown that the following gene products are overexpressed during infectious processes, especially during the infection of human macrophages: CtpF, CtpG, CtpV, CtpC, CtpA, CtpH, and CtpI (Figure 2). The overexpression of these genes highlights the importance of P-type ATPases in TB infection. Interestingly, the $c_{p} E$ gene is the only gene that is downregulated during $M t b$ infection. Finally, it is worth noting that no changes were observed in the expression of the heavy metal transporter CtpJ under the stress conditions shown in Table 2. These observations strongly suggest that P-type ATPases might play essential roles during the $M t b$ infection process and that their inhibition could affect the viability and/or virulence of the tubercle bacilli.

\section{Divergence of the Mycobacterium tuberculosis P-Type ATPases}

P-type ATPases share the same catalytic mechanism, independent of their origin and ion specificity $[15,19,20]$. On the other hand, to use $M t b$ P-type ATPases as therapeutic targets, it is important that differences exist between the human and mycobacterial P-type ATPases to avoid cross-reactions with the host cells [30].

\subsection{P-Type ATPases Are Well Conserved in the Mycobacterium} tuberculosis Complex. Preferably, a therapeutic target must be present in other pathogens belonging to the same taxonomic class, due to the fact that an inhibitor designed against a particular infectious agent may be able to act against an infection caused by any one or several of its phylogenetically related pathogens. Regarding $M t b$ P-type ATPases, it has been observed that this type of transporters is quite well conserved in the $M t b$ complex, with at least $98 \%$ identity in their amino acid sequences [22]. This high similarity may be advantageous, as the inhibitor of a particular $M t b$ P-type ATPase could be active against other members of the $M t b$ complex, which can also cause serious infectious diseases. From the experimental point of view, the fact that the attenuated and virulent $M t b, \mathrm{H} 37 \mathrm{Ra}$, and $\mathrm{H} 37 \mathrm{Rv}$ strains share an identical Ptype ATPase sequence [22] is an advantage because it gives to the investigator the possibility to work with the attenuated and biosafe H37Ra strain, which vastly simplifies the experimental procedures oriented towards the characterization of these enzymes. Additionally, an interesting and ambitious option would be to exploit the similarities between the $M t b$ P-type ATPases to design inhibitors that can block several of these transporters. For example, the mycobacterial CtpA and $\mathrm{CtpB}$ transporters are predicted to be $\mathrm{Cu}^{1+} \mathrm{P}_{\mathrm{IB}-1}$-type ATPases, and these enzymes share $68 \%$ identity in their amino acid sequences (see Figure S1 in Supplementary Material available online at http://dx.doi.org/10.1155/2014/296986) [22]. Thus, if an inhibitor is designed against one of these transporters, it is very likely that such an inhibitor could be active against the other enzyme.
6.2. Divergence between the Mycobacterial and Human PType ATPases. Table 1 shows that CtpE, CtpH, CtpJ, and CtpD are the most divergent $M t b$ P-type ATPases compared with their human counterparts; thus, these enzymes are the most likely to be inhibited without affecting the host cells. Conversely, CtpF, CtpV, CtpA, and CtpB are closer to human P-type ATPases, with similarities lower than $57 \%$. This implies that, at any rate, $M t b$ P-type ATPase pumps contain a considerable proportion of divergent sequences, potential targets for inhibitor compounds. Trying to avoid possible cross-reactions of the $M t b$ P-type ATPase inhibitors with the host, the development of prodrugs, which can be converted into their active forms in the intraphagosomal environment or as products of mycobacterial metabolism, could be an interesting strategy for the discovering of new antituberculous drugs. This approach has been used successfully in other cases, including the omeprazole and thapsigargin prodrugs, which inhibit tissue-specific P-type ATPases [29].

\section{Mtb P-Type ATPases as Virulence Factors}

Virulence factors are involved in the invasion and persistence of pathogens inside the hosts, as well as in disease manifestations [53]. In this sense, P-type ATPases are required for the virulence of several bacterial pathogens, such as Pseudomonas aeruginosa and Streptococcus pneumoniae [27, 54-56]. Recent studies on the $M t b$ complex have considered the heavy metal cation transporters CtpC and $\mathrm{CtpV}$ as virulence factors whose inhibition may induce an attenuation of the tubercle bacilli [23]. However, phenotypic studies have shown that the deletion of these pumps does not result in a complete loss of virulence, suggesting the existence of compensatory mechanisms among these enzymes.

\section{Mycobacterium tuberculosis P-Type ATPases in the Development of Novel Vaccines}

The large number of P-type ATPases encoded in the tubercle bacillus genome suggests the evolutionary importance of $M t b$ metal cation homeostasis [17, 22]. According to this assumption, the tubercle bacillus apparently developed a compensatory strategy involving the P-type ATPases, in which the suppression of one P-type pump is counterbalanced by the overexpression of another P-type ATPase with similar activity [11]. Interestingly, it has been observed that the deletion of CtpV, one of the Mtb P-type ATPases, leads to an attenuation of the $\Delta c t p V$ mutant compared with other mycobacterial strains [17]. Then, this mechanism opens a window for the design of attenuated anti-TB vaccines and allows the construction of mycobacterial mutant strains, null in multiple P-type ATPase genes. This strategy represents a promising option for the development of a novel, live vaccine to replace the current, questionable BCG vaccine [11]. 


\section{Conclusions and Outlooks}

In general, most $M t b$ P-ATPases modify their expression profiles when the mycobacteria face stressful conditions, such as the presence of toxic substances, latency infection, and active disease, suggesting that these transporters may be part of the strategies used by tubercle bacilli to colonize, interact with, and/or alter the functions of the host cells. In light of these behaviors, we suggest two strategies for the rational design of Mtb P-type ATPases inhibitors: (i) blocking the $M t b$ P-type ATPases that are overexpressed under stress conditions, as these enzymes might be required for the persistence of the pathogen during infection and their inhibition may compromise $M t b$ viability, and/or (ii) activating the P-type ATPases during the dormant phase of $M t b$ infection to alter the strict homeostasis required by $M t b$ to survive during this process. Additionally, P-type ATPases are very well conserved among the $M t b$ complex; this may be advantageous because a potential inhibitor designed against any Mtb Ptype ATPase could be active against other members of the $M t b$ complex, thereby combating the serious health problem caused by TB worldwide. Another remarkable feature is the considerable divergence between human and mycobacterial P-type ATPases, which makes the latter potential targets for novel anti-TB drugs. Finally, the apparent existence of compensatory mechanisms among $M t b$ P-type ATPases and the possible attenuation related to the deletion of this kind of transporters open the possibility for the design of new, antiTB attenuated vaccines to replace the current BCG vaccine. Of course, further research must be performed to evaluate the applicability, advantages, and disadvantages of these targets, taking into account that it is essential for new drugs to be economical, as $94 \%$ of $\mathrm{TB}$ cases occur in extremely poor societies.

\section{Conflict of Interests}

The authors declare that there is no conflict of interests regarding the publication of this paper.

\section{Acknowledgments}

This work was supported by the "División de Investigación Bogotá, DIB," Vicerrectoría de Investigación, Universidad Nacional de Colombia, Grants 15835, 16060, and 18726. LNA is a Fellow of the "Vicerrectoría Académica," Universidad Nacional de Colombia.

\section{References}

[1] TB-Alliance, Global Alliance for TB Drug Development-2012 Annual Report, 2012.

[2] WHO, Global tuberculosis report 2013, 2013.

[3] N. A. Knechel, "Tuberculosis: pathophysiology, clinical features, and diagnosis," Critical Care Nurse, vol. 29, no. 2, pp. 34-44, 2009.

[4] D. J. Murphy and J. R. Brown, "Identification of gene targets against dormant phase Mycobacterium tuberculosis infections," BMC Infectious Diseases, vol. 7, article 84, 2007.
[5] K. Pethe, D. L. Swenson, S. Alonso, J. Anderson, C. Wang, and D. G. Russell, "Isolation of Mycobacterium tuberculosis mutants defective in the arrest of phagosome maturation," Proceedings of the National Academy of Sciences of the United States of America, vol. 101, no. 37, pp. 13642-13647, 2004.

[6] C. L. Cosma, D. R. Sherman, and L. Ramakrishnan, "The secret lives of the pathogenic mycobacteria," Annual Review of Microbiology, vol. 57, pp. 641-676, 2003.

[7] V. Sundaramurthy and J. Pieters, "Interactions of pathogenic mycobacteria with host macrophages," Microbes and Infection, vol. 9, no. 14-15, pp. 1671-1679, 2007.

[8] P. G. But, R. A. Murav'ev, V. A. Fomina, and V. V. Rogovin, "Intracellular transformation of phagosomes," Biology Bulletin, vol. 31, no. 6, pp. 564-567, 2004.

[9] V. A. Kelley and J. S. Schorey, "Mycobacterium's arrest of phagosome maturation in macrophages requires Rab5 activity and accessibility to iron," Molecular Biology of the Cell, vol. 14, no. 8, pp. 3366-3377, 2003.

[10] G. M. Cook, M. Berney, S. Gebhard et al., "Physiology of mycobacteria," Advances in Microbial Physiology, vol. 55, pp. 81182, 318-319, 2009.

[11] H. Botella, P. Peyron, F. Levillain et al., "Mycobacterial P 1Type ATPases mediate resistance to Zinc poisoning in human macrophages," Cell Host and Microbe, vol. 10, no. 3, pp. 248-259, 2011.

[12] C. E. Barry III, H. I. Boshoff, V. Dartois et al., "The spectrum of latent tuberculosis: rethinking the biology and intervention strategies," Nature Reviews Microbiology, vol. 7, no. 12, pp. 845855, 2009.

[13] S. H. Cho, D. Goodlett, and S. Franzblau, "ICAT-based comparative proteomic analysis of non-replicating persistent Mycobacterium tuberculosis," Tuberculosis, vol. 86, no. 6, pp. 445-460, 2006.

[14] A. Koul, E. Arnoult, N. Lounis, J. Guillemont, and K. Andries, "The challenge of new drug discovery for tuberculosis," Nature, vol. 469, no. 7331, pp. 483-490, 2011.

[15] M. G. Palmgren and P. Nissen, "P-Type ATPases," Annual Review of Biophysics, vol. 40, no. 1, pp. 243-266, 2011.

[16] H. Chan, V. Babayan, E. Blyumin et al., "The P-type ATPase superfamily," Journal of Molecular Microbiology and Biotechnology, vol. 19, no. 1-2, pp. 5-104, 2010.

[17] S. K. Ward, B. Abomoelak, E. A. Hoye, H. Steinberg, and A. M. Talaat, "CtpV: a putative copper exporter required for full virulence of Mycobacterium tuberculosis," Molecular Microbiology, vol. 77, no. 5, pp. 1096-1110, 2010.

[18] P. Chène, "ATPases as drug targets: learning from their structure," Nature Reviews Drug Discovery, vol. 1, no. 9, pp. 665-673, 2002.

[19] W. Kuhlbrandt, "Biology, structure and mechanism of P-type ATPases," Nature Reviews Molecular Cell Biology, vol. 5, no. 4, pp. 282-295, 2004.

[20] M. D. Thever and M. H. Saier Jr., "Bioinformatic characterization of P-Type ATPases encoded within the fully sequenced genomes of 26 eukaryotes," Journal of Membrane Biology, vol. 229, no. 3, pp. 115-130, 2009.

[21] K. B. Axelsen and M. G. Palmgren, "Evolution of substrate specificities in the P-type ATPase superfamily," Journal of Molecular Evolution, vol. 46, no. 1, pp. 84-101, 1998.

[22] L. Novoa-Aponte, A. León-Torres, M. Patiño-Ruiz et al., "In silico identification and characterization of the ion transport specificity for P-type ATPases in the Mycobacterium tuberculosis complex," BMC Structural Biology, vol. 12, no. 1, article 25, 2012. 
[23] M. A. Forrellad, L. I. Klepp, A. Gioffré et al., "Virulence factors of the mycobacterium tuberculosis complex," Virulence, vol. 4, no. 1, pp. 3-66, 2013.

[24] I. V. N. M. Rathnayake, M. Bolan, and R. Naidu, Tolerance of Heavy Metals by Gram Positive Soil Bacteria, vol. 53, World Academy of Science, Engineering and Technology, 2009.

[25] SmegmaList, http://mycobrowser.epfl.ch/smegmalist.html.

[26] D. Raimunda, J. E. Long, C. M. Sassetti, and J. M. Argüello, "Role in metal homeostasis of CtpD, a Co ${ }^{2+}$ transporting $\mathrm{P}_{1 B 4}$-ATPase of Mycobacterium smegmatis," Molecular Microbiology, vol. 84, no. 6, pp. 1139-1149, 2012.

[27] J. M. Argüello, M. González-Guerrero, and D. Raimunda, "Bacterial transition metal P1B-ATPases: transport mechanism and roles in virulence," Biochemistry, vol. 50, no. 46, pp. 99409949, 2011.

[28] C. M. Sassetti and E. J. Rubin, "Genetic requirements for mycobacterial survival during infection," Proceedings of the National Academy of Sciences of the United States of America, vol. 100, no. 22, pp. 12989-12994, 2003.

[29] L. Yatime, M. J. Buch-Pedersen, M. Musgaard et al., "P-type ATPases as drug targets: tools for medicine and science," Biochim Biophys Acta, vol. 1787, no. 4, pp. 207-220, 2009.

[30] S. Hasan, S. Daugelat, P. S. S. Rao, and M. Schreiber, "Prioritizing genomic drug targets in pathogens: application to Mycobacterium tuberculosis," PLoS Computational Biology, vol. 2, no. 6, p. e61, 2006.

[31] A. M. Talaat, R. Lyons, S. T. Howard, and S. A. Johnston, "The temporal expression profile of Mycobacterium tuberculosis infection in mice," Proceedings of the National Academy of Sciences of the United States of America, vol. 101, no. 13, pp. 46024607, 2004.

[32] A. Chatterjee, D. Saranath, P. Bhatter, and N. Mistry, "Global transcriptional profiling of longitudinal clinical isolates of Mycobacterium tuberculosis exhibiting rapid accumulation of drug resistance," PLoS ONE, vol. 8, no. 1, Article ID e54717, 2013.

[33] R. Manganelli, M. I. Voskuil, G. K. Schoolnik, and I. Smith, "The Mycobacterium tuberculosis ECF sigma factor $\sigma$ E: role in global gene expression and survival in macrophages," Molecular Microbiology, vol. 41, no. 2, pp. 423-437, 2001.

[34] S. J. Waddell, R. A. Stabler, K. Laing, L. Kremer, R. C. Reynolds, and G. S. Besra, "The use of microarray analysis to determine the gene expression profiles of Mycobacterium tuberculosis in response to anti-bacterial compounds," Tuberculosis, vol. 84, no. 3-4, pp. 263-274, 2004.

[35] H. Jang, C. Nde, F. Toghrol, and W. E. Bentley, "Global transcriptome analysis of the Mycobacterium bovis BCG response to sodium hypochlorite," Applied Microbiology and Biotechnology, vol. 85, no. 1, pp. 127-140, 2009.

[36] C. W. Nde, F. Toghrol, H. Jang, and W. E. Bentley, "Toxicogenomic response of Mycobacterium bovis BCG to peracetic acid and a comparative analysis of the M. bovis BCG response to three oxidative disinfectants," Applied Microbiology and Biotechnology, vol. 90, no. 1, pp. 277-304, 2011.

[37] R. Manganelli, M. I. Voskuil, G. K. Schoolnik, E. Dubnau, M. Gomez, and I. Smith, "Role of the extracytoplasmic-function $\sigma$ factor $\sigma \mathrm{H}$ in Mycobacterium tuberculosis global gene expression," Molecular Microbiology, vol. 45, no. 2, pp. 365-374, 2002.

[38] H. Ohno, G. Zhu, V. P. Mohan et al., "The effects of reactive nitrogen intermediates on gene expression in Mycobacterium tuberculosis," Cellular Microbiology, vol. 5, no. 9, pp. 637-648, 2003.
[39] S. K. Ward, E. A. Hoye, and A. M. Talaat, "The global responses of Mycobacterium tuberculosis to physiological levels of copper," Journal of Bacteriology, vol. 190, no. 8, pp. 2939-2946, 2008.

[40] D. R. Sherman, M. Voskuil, D. Schnappinger, R. Liao, M. I. Harrell, and G. K. Schoolnik, "Regulation of the Mycobacterium tuberculosis hypoxic response gene encoding $\alpha$-crystallin," Proceedings of the National Academy of Sciences of the United States of America, vol. 98, no. 13, pp. 7534-7539, 2001.

[41] J. Bacon, B. W. James, L. Wernisch et al., "The influence of reduced oxygen availability on pathogenicity and gene expression in Mycobacterium tuberculosis," Tuberculosis, vol. 84, no. 3-4, pp. 205-217, 2004.

[42] M. I. Voskuil, D. Schnappinger, K. C. Visconti et al., "Inhibition of respiration by nitric oxide induces a Mycobacterium tuberculosis dormancy program," Journal of Experimental Medicine, vol. 198, no. 5, pp. 705-713, 2003.

[43] S. L. Kendall, F. Movahedzadeh, S. C. G. Rison et al., "The Mycobacterium tuberculosis dosRS two-component system is induced by multiple stresses," Tuberculosis, vol. 84, no. 3-4, pp. 247-255, 2004.

[44] D. G. N. Muttucumaru, G. Roberts, J. Hinds, R. A. Stabler, and T. Parish, "Gene expression profile of Mycobacterium tuberculosis in a non-replicating state," Tuberculosis, vol. 84, no. 3-4, pp. 239246, 2004.

[45] T. Hampshire, S. Soneji, J. Bacon et al., "Stationary phase gene expression of Mycobacterium tuberculosis following a progressive nutrient depletion: a model for persistent organisms?" Tuberculosis, vol. 84, no. 3-4, pp. 228-238, 2004.

[46] J. C. Betts, P. T. Lukey, L. C. Robb, R. A. McAdam, and K. Duncan, "Evaluation of a nutrient starvation model of Mycobacterium tuberculosis persistence by gene and protein expression profiling," Molecular Microbiology, vol. 43, no. 3, pp. 717-731, 2002.

[47] D. Schnappinger, S. Ehrt, M. I. Voskuil et al., "Transcriptional adaptation of Mycobacterium tuberculosis within macrophages: Insights into the phagosomal environment," Journal of Experimental Medicine, vol. 198, no. 5, pp. 693-704, 2003.

[48] P. C. Karakousis, T. Yoshimatsu, G. Lamichhane et al., "Dormancy phenotype displayed by extracellular Mycobacterium tuberculosis within artificial granulomas in mice," Journal of Experimental Medicine, vol. 200, no. 5, pp. 647-657, 2004.

[49] L. Tailleux, S. J. Waddel, M. Pelizolla et al., "Probing host pathogen cross-talk by transcriptional profiling of both Mycobacterium tuberculosis and infected human dendritic cells and macrophages," PLoS ONE, vol. 3, no. 1, Article ID e1403, 2008.

[50] M. Kumar, F. G. Khan, S. Sharma et al., "Identification of Mycobacterium tuberculosis genes preferentially expressed during human infection," Microbial Pathogenesis, vol. 50, no. 1, pp. 31-38, 2011.

[51] H. D. Park, K. M. Guinn, M. I. Harrell et al., "Rv3133c/dosR is a transcription factor that mediates the hypoxic response of Mycobacterium tuberculosis," Molecular Microbiology, vol. 48, no. 3, pp. 833-843, 2003.

[52] K. Andries, P. Verhasselt, J. Guillemont et al., "A diarylquinoline drug active on the ATP synthase of Mycobacterium tuberculosis," Science, vol. 307, no. 5707, pp. 223-227, 2005.

[53] H. Rachman, M. Strong, U. Schaible et al., "Mycobacterium tuberculosis gene expression profiling within the context of protein networks," Microbes and Infection, vol. 8, no. 3, pp. 747$757,2006$. 
[54] J. Neef, V. F. Andisi, K. S. Kim, O. P. Kuipers, and J. J. E. Bijlsma, "Deletion of a cation transporter promotes lysis in Streptococcus pneumoniae," Infection and Immunity, vol. 79, no. 6, pp. 2314-2323, 2011.

[55] W. R. Schwan, P. Warrener, E. Keunz, C. Kendall Stover, and K. R. Folger, "Mutations in the cueA gene encoding a copper homeostasis P-type ATPase reduce the pathogenicity of Pseudomonas aeruginosa in mice," International Journal of Medical Microbiology, vol. 295, no. 4, pp. 237-242, 2005.

[56] T. Soldati and O. Neyrolles, "Mycobacteria and the intraphagosomal environment: take it with a pinch of salt(s)!," Traffic, vol. 13, no. 8, pp. 1042-1052, 2012. 


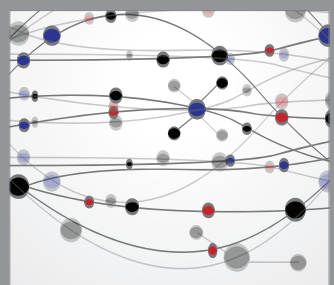

The Scientific World Journal
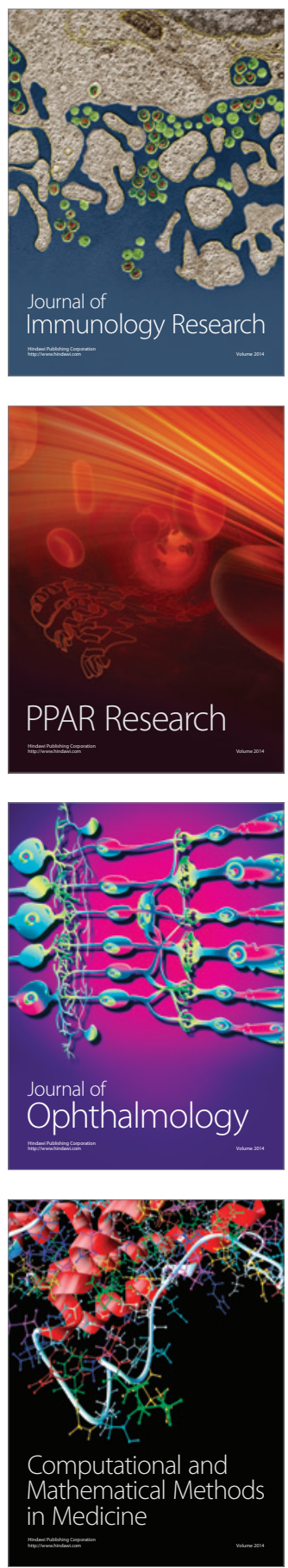

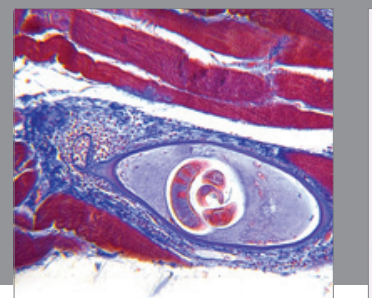

Gastroenterology

Research and Practice
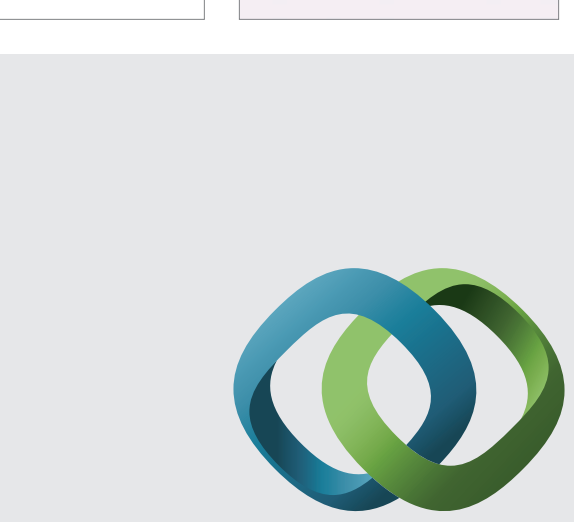

\section{Hindawi}

Submit your manuscripts at

http://www.hindawi.com
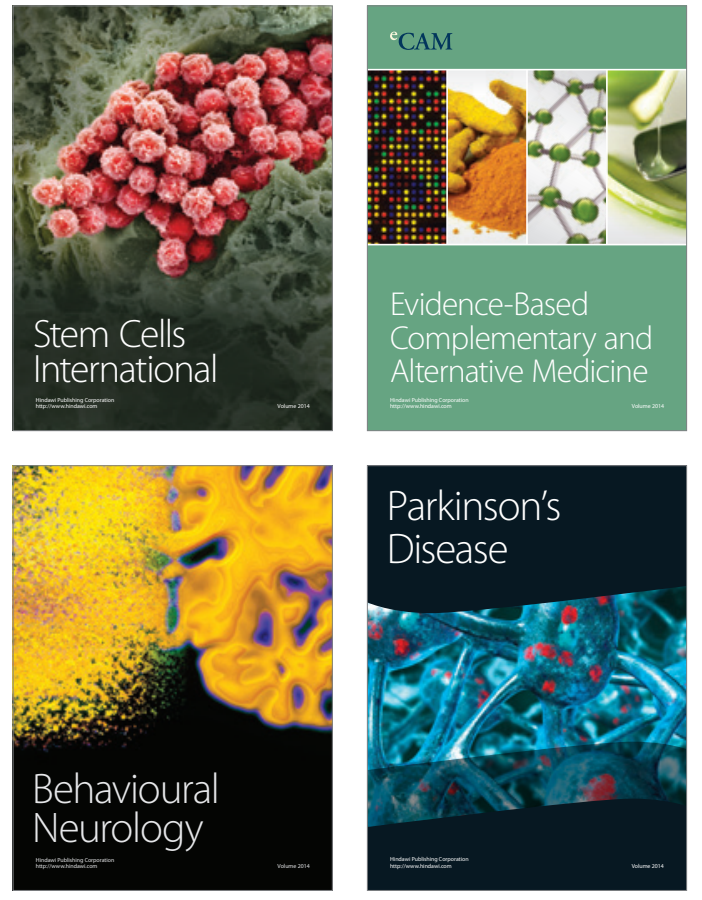
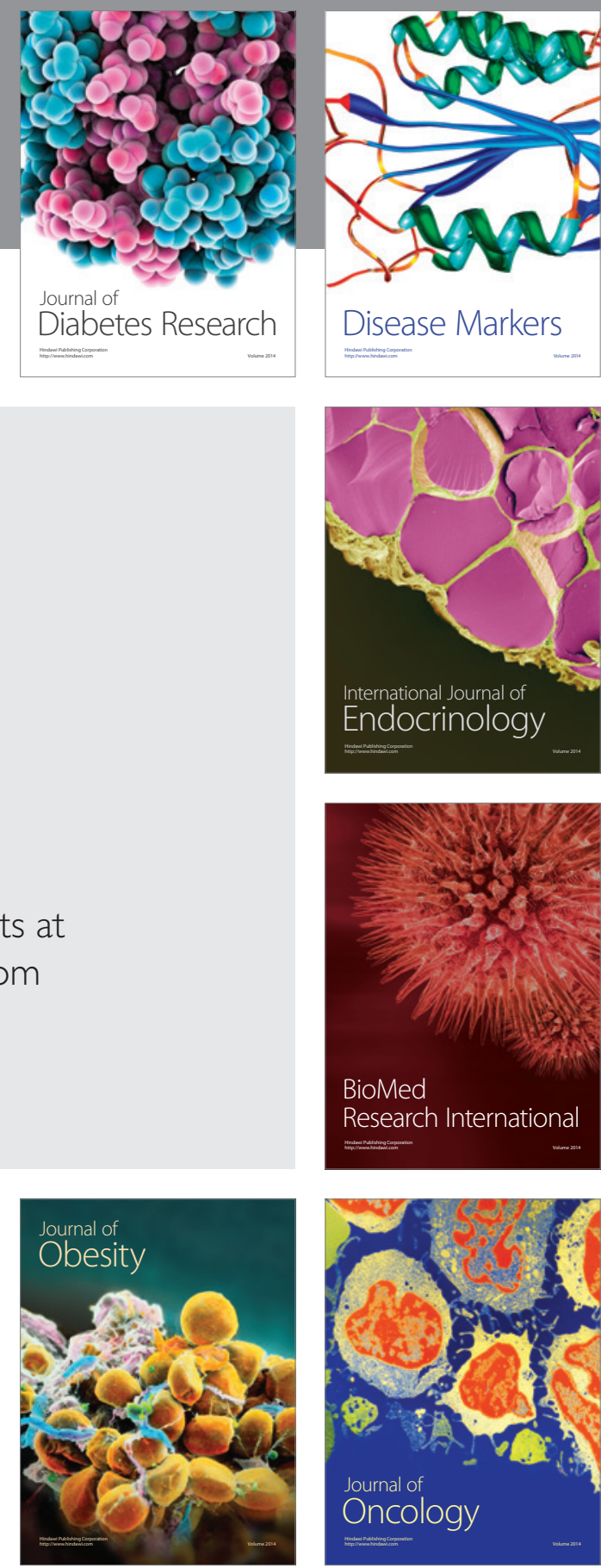

Disease Markers
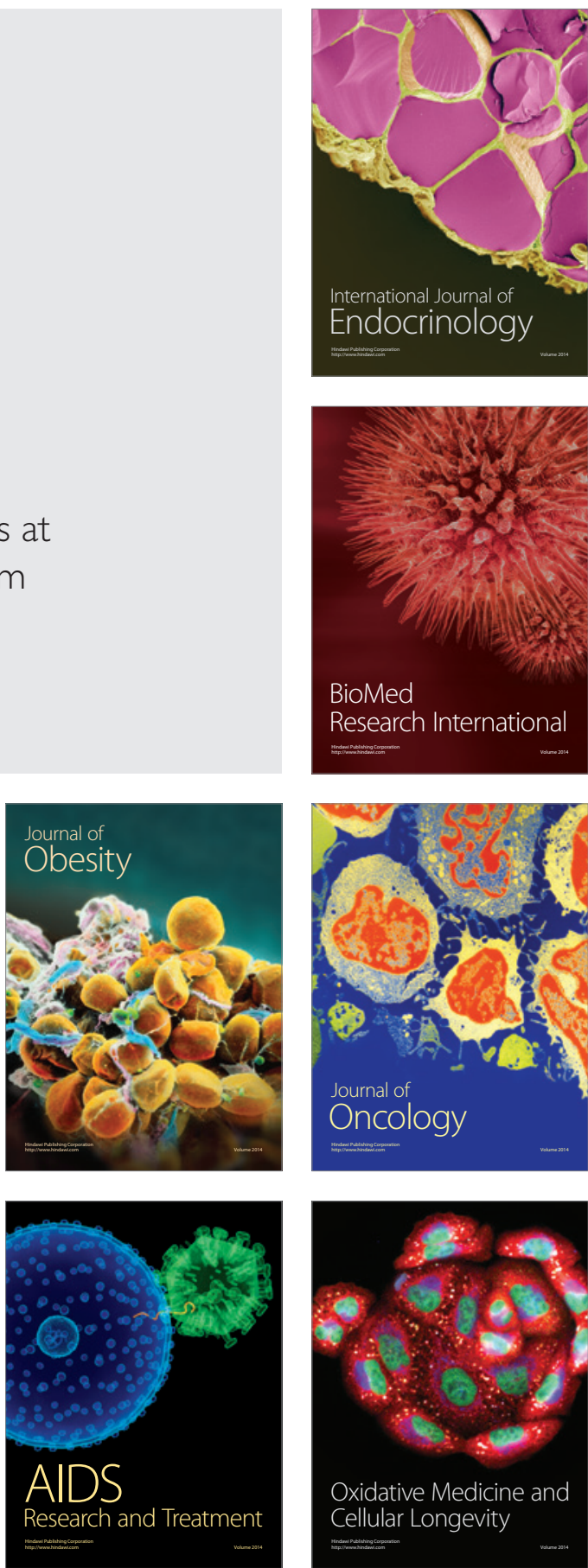